by

\author{
Heather Robbins \\ BA, University of Manitoba, 1999 \\ MA, University of Toronto, 2002 \\ A Major Research Paper \\ presented to Ryerson University \\ in partial fulfillment of the requirements for the degree of \\ Master of Arts \\ in the Program of \\ Immigration and Settlement Studies
}

Toronto, Ontario, Canada, 2009

(C) Heather Robbins 2009 


\title{
PRE-MIGRATION PREPARATION AND THE LABOUR MARKET INTEGRATION OF SKILLED IMMIGRANTS
}

\author{
Heather Robbins \\ Master of Arts, 2009 \\ Immigration and Settlement Studies \\ Ryerson University
}

\begin{abstract}
Canada has been attracting higher numbers of skilled immigrants in order to address labour shortages and fuel economic growth, yet the labour market outcomes of this group remain disappointingly poor. While a variety of initiatives have been introduced by the federal government to address the situation once skilled immigrants have arrived in Canada, recent attention has focused on preparing them for the labour market while they are still in their home country. These pre-migration preparation initiatives consist of the provision of information, referral and path-finding via online resources and in-person services. This paper will examine each initiative in order to evaluate its content and delivery system and to determine how effectively pre-migration initiatives allow skilled immigrants to prepare for the Canadian labour market and to what extent they contribute to the improvement of labour market integration. The paper also considers the key role played by the regulatory bodies and employers.
\end{abstract}

Key terms: skilled immigrants; pre-migration preparation; overseas; pre-arrival; labour market integration; economic integration; outcomes; labour market barriers; federal initiatives; regulatory bodies; employers 


\section{Acknowledgements}

I would like to thank my supervisor, Arthur Ross, for his generous support and for sharing his knowledge and experience with me. My appreciation also goes to Patrice

Dutil, who served as my second reader. In addition, I am greatly indebted to all of my wonderful professors from whom I learned far more than can be measured. Lastly, thanks to my husband for his encouragement. 


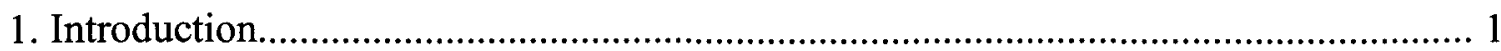

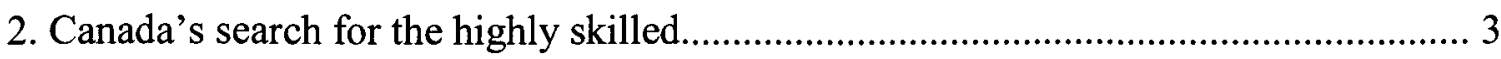

3. Poor economic outcomes of skilled immigrants............................................................ 5

4. Barriers for skilled immigrants in the labour market.................................................. 10

5. Disjuncture between federal selection policy and the labour market.......................... 17

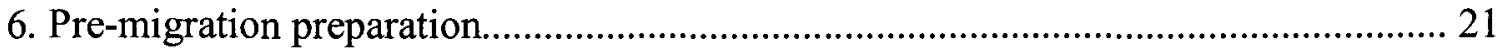

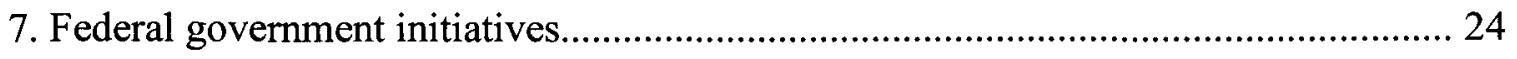

7.1 Canadian Orientation Abroad...................................................................... 24

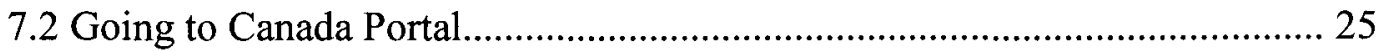

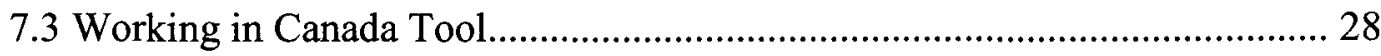

7.4 Foreign Credentials Referral Office, Essential Workbook.............................. 31

7.5 Foreign Credentials Referral Office, Canadian Immigration Integration

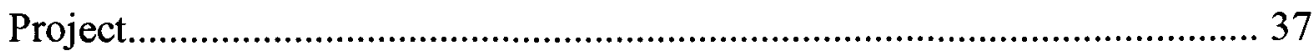

8. The role of the regulated bodies in pre-migration preparation.................................... 45

9. The role of employers in pre-migration preparation................................................... 51

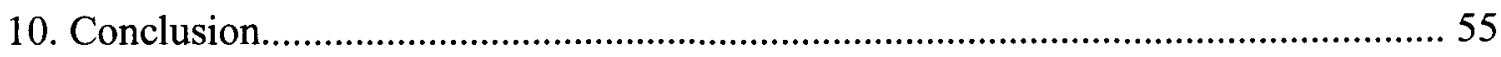

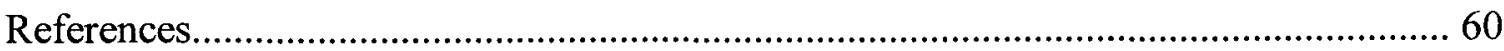




\section{Introduction}

With the rise of the global knowledge-based economy, Canada has been engaging in an aggressive hunt for the highly skilled in order to address growing labour shortages and fuel economic growth. Its efforts have been successful. The education levels of immigrants to the country have increased significantly over the past two decades, reaching record heights in the last 2006 Census (Statistics Canada, 2006a). While education levels have been rising, however, the economic outcomes of skilled immigrants have remained embarrassingly poor. These imported knowledge workers are failing to find employment in the knowledge occupations for which the federal government marked them, and are instead disproportionately represented in jobs far below their skill level.

The waste of human capital inherent in this situation and the cost to the economy are often cited (Bloom and Grant, 2001; Reitz, 2001a). More important, however, is the cost to the skilled immigrants themselves who arrive in Canada with the expectation of finding employment in their field, only to see their hopes defeated and financial resources depleted as their efforts to practice their profession are derailed. This has led many to question the purpose and direction of Canada's economic immigration program. If the federal government is devoting so much effort to attracting the highly skilled to fill labour shortages, and yet failing to plug them into the positions for which they were destined, is the program not a failure?

A variety of initiatives have been introduced by the federal government to address the poor economic outcomes of skilled immigrants. For the most part, these have focused on foreign credential recognition and the strengthening of settlement programs, including the expansion of Bridge Training and Enhanced Language Training. While these responses focus on the problem once skilled immigrants have arrived in Canada, over the 
past five years, increasing attention has been given to initiatives to prepare them for the labour market while they are still in their home country. Such pre-migration preparation consists of the provision of information, referral and path-finding services that are delivered online and in person in select cities abroad. The resources allow skilled immigrants to obtain relevant labour market information in order to assess their employment prospects and make informed decisions, and to identify and proceed on a pathway to registration or employment in their profession. The overall purpose of the government's pre-migration preparation is to expedite entry into the labour market at a level commensurate with immigrants' education and experience by allowing them to circumvent many of the existing barriers to integration.

A recent commitment of programs and funding has identified pre-migration preparation as a priority for the federal government. In-person services, for example, will be expanded in 2010 . The preparation initiatives are also being touted as a marketing tool that will help Canada appear more attractive to global talent because of their ability to accelerate labour market entry. These initiatives are therefore a significant part of the current strategy to remedy the embarrassing and pressing issue of the economic integration of skilled immigrants. The topic of pre-migration preparation has nowhere been examined, however, and only one of the online resources has been evaluated.

This paper aims to address the gap in knowledge regarding pre-migration preparation. First, it will consider the broad context of the economic integration of skilled immigrants and the circumstances that have led to a need for pre-migration preparation. Second, the paper will examine the online resources and in-person services developed by the federal government in order to evaluate their content and delivery system to determine how effectively they allow immigrants to prepare for the Canadian labour 
market and to what extent they can contribute to the improvement of labour market integration.

\section{Canada's search for the highly skilled}

With the rise of the global knowledge-based economy, Canada has been seeking greater numbers of highly skilled immigrants. According to academics, policy makers and the media, this new economy increasingly necessitates human capital, skills, innovation and technology for growth and competition (Baldwin and Beckstead, 2003). In 2002, in conjunction with the government's Innovation Strategy, Human Resources and Skills Development Canada released a paper elucidating what the knowledge-based economy entails for Canada's labour force. The report, entitled Knowledge Matters:

Skills and Learning for Canadians, explains the ways in which work and business have been revolutionized by information and communications technologies, leading to the emergence of new products, firms and industries. This has resulted in the creation of new kinds of occupations and a transformation of the skills required for conventional occupations.

Both the new and conventional occupations require higher levels of education. As the report relates, this means "an ever-increasing demand for a well-educated and skilled workforce in all parts of the economy and in all parts of the country". And indeed, Baldwin and Beckstead's study on knowledge workers in Canada's economy shows that, between 1971 and 2001, the number of such workers has almost doubled (2003). Over those last three decades, there has been a gradual yet steady shift towards a more highly skilled workforce across all industries and sectors.

Labour shortages due to a lack of qualified skilled workers have been identified and 
Canada's ageing population and low fertility rate will only continue to exacerbate them. A report by the Canadian Federation of Independent Business (2000) identified vacancies upwards of 300,000 already in the year 2000 and the Conference Board of Canada (2000) has projected the number will mount to close to one million by 2020 . Therefore, a crucial role has been attributed to skilled immigration in the filling of labour shortages necessary to fuel the growth of the Canadian economy.

Much emphasis has been placed on the aspect of global competition for knowledge workers. Other developed countries, including Australia, the U.S., New Zealand, and many European Union countries, are facing similar skills shortages and demographic challenges along with the same growing need for a highly educated workforce. A report by the Asia Pacific Foundation of Canada explains that there is a global scarcity of skills and the import of international labour is part of a process of skills redistribution (2005). As a result, Canada must work hard to attract the knowledge workers it needs in competition with other countries. This is continuously alluded to in speeches and news releases by both federal and provincial ministers for immigration, labour and industry. A paper released by Human Resources and Skills Development Canada states that it aims for $65 \%$ of immigrants to have a post-secondary education by the year 2010 , up from $58 \%$ in 2000 . Canada is therefore engaged in an aggressive hunt for the highly skilled.

The number of highly educated immigrants entering Canada has in fact been increasing over time. In the 1980 s, roughly $23 \%$ of immigrants arrived with a university degree (Grant and Sweetman, 2004). In the 1990s, this number jumped to $40 \%$, and the latest Census data show that it has again risen to 51\% for those arriving between 2001 and 2006. The percentage of the Canadian born with degrees is far lower, at $23 \%$ in the 1990s and 20\% between 2001 and 2006 (Statistics Canada, 2006a). 
The jump in education for immigrants in the 1990s came largely as a result of changes introduced in a new federal immigration policy framework in 1995. In Into the $21^{\text {st }}$ Century: A Strategy for Immigration and Citizenship, inflow targets were increased, as was the proportion of points-assessed immigrants in the inflow. The number of points allotted to skills and education was augmented as well. As Green and Green describe, the new policy was guided by the notion that large inflows selected for high skill levels would form a flexible workforce that could generate substantial economic growth (2004). A ratio of roughly $60: 40$ of economic to family and humanitarian immigrants has been maintained ever since along with the premium on higher education (Hiebert, 2006).

In addition to high education levels, the data also show that immigrants are arriving with a high level of occupational skill and an average of seven years more work experience than the Canadian born (Ferrer and Riddell, 2004). Hiebert demonstrates that among immigrants arriving between 1995 and 2004 with some prior labour market experience, $58 \%$ of the total inflow were professionals, while $9.4 \%$ had managerial experience and $21.3 \%$ had intermediate or clerical skill levels (2006). Only $1 \%$ of immigrants arrived with elemental skills.

\section{Poor economic outcomes of skilled immigrants}

Despite the high number of skilled immigrants arriving in Canada, their economic outcomes have been embarrassingly poor. The most obvious indication of this is the acute gap in earnings between the Canadian born and recent immigrants (those in Canada under five years) which has been widening since the 1980s. A study by Frenette and Morrissette shows that the difference in earnings doubled overall between 1980 and 2000 while the education levels of Canada's immigrant inflow rose (2003). In 1980, the earnings of 
recent immigrants were $13 \%$ lower than those of the native born and in 1985 , they dropped to $31 \%$ lower. There was no change in 1990 , although the deterioration resumed in 1995 , hitting $45 \%$, while subsequently moving back up to $31 \%$ in 2000 . The pattern presented by Frenette and Morrissette confirms the findings of previous research (Baker and Benjamin, 1994; Bloom, Grenier and Gunderson, 1995; Grant, 1999; Green and Worswick, 2003) and is also supported by later studies (Warman and Worswick, 2004; Aydemir and Skuterud, 2004; Picot, 2004).

An analysis of earnings and incomes of Canadians based on the 2006 Census by Statistics Canada specifically compares the earnings of immigrants with university degrees to those of similarly-educated Canadian born workers. In 1980, immigrant males who had arrived within five years earned $77 \%$ of their Canadian born counterparts. This shrank to $63 \%$ in 1990 , and then to $58 \%$ in 2000 and $48 \%$ in 2005 . Recent immigrant females also earned much less than their Canadian born counterparts, and while the rate rose from $59 \%$ in 1980 to $63 \%$ in 1990 , it dropped again to $52 \%$ in 2000 and $43 \%$ in 2005. In fact, the analysis shows the gap for immigrants with a university degree has been wider than for those without. For example, while males with a degree earned $48 \%$ of the Canadian born in 2005, those without a degree earned $61 \%$ of the Canadian born (Statistics Canada, 2006a).

Research shows that the earnings of the foreign born do improve with time in Canada, but the widening gap observed at entry is disturbing and, indeed, debilitating. Frenette and Morrissette demonstrate that cohorts entering in the late 1970s almost reached earnings parity with Canadians with comparable characteristics after twenty years (2003). After the same period of time, however, those entering in the early 1980s were still fifteen percentage points behind because of the drop in initial earnings they 
experienced. The rate of improvement in earnings in the 1990s was much greater than the previous decade, and yet Frenette and Morrissette's research shows the acute drop in wages at entry experienced by newcomers at that time has all but guaranteed that earnings will never catch up.

Unemployment rates have been higher for recent immigrants with degrees as well. Using Census data, Hawthorne shows that in 2001, the unemployment rate for the university educated who had been in Canada for over ten years was $4.1 \%$, compared to $3.8 \%$ for the similarly educated Canadian born (2007). For immigrants in Canada between five and ten years, though, it was $7.9 \%$, and for those under 5 years, it was a whopping $14.7 \%$. This constitutes a gap of roughly $11 \%$. By contrast, the gap in unemployment rates for immigrants without any post-secondary education was between 2.5 and $4.5 \%$. Zietsma's analysis of the 2006 Labour Force Survey reveals similar results for the most recent period (2007). Unemployment rates for recent university-educated immigrants were $11.5 \%$ compared to $4.9 \%$ for those born in Canada. The survey also reveals that the possession of higher education did nothing to improve the unemployment rates of immigrants, whereas the rates for the Canadian born decreased as educational attainment increased. While immigrants arriving in Canada are now twice as likely as the Canadian born to have a university education, they are twice as likely to be unemployed.

Studies show that highly skilled immigrants are not finding employment in the knowledge occupations for which the federal government marked them, but are instead frequently taking up low skilled jobs. Examining census data from 1991 to 2001, Galarneau and Morrissette found that one in four recent immigrants with a university degree held a job during that period which required no more than a high school education (2004). An analysis by Statistics Canada also demonstrates that the majority of immigrant 
men with a university degree who arrived in the 1990s were employed in twenty-nine low skilled occupations (2003a). As the study explains, those occupations included "restaurant and food service managers, taxi and limousine drivers and chauffeurs, truck drivers, security guards and related occupations and janitors, caretakers and building superintendents" (p.13). What is more, the same study shows these immigrants still earned less than the Canadian born in the same jobs.

While the number of knowledge occupations in Canada has been increasing as demonstrated by Baldwin and Beckstead, immigrants are obviously having difficulty accessing these jobs (2003). Research by Reitz on the representation of immigrants in knowledge occupations reveals that in 1996, only $35 \%$ of recent immigrant men with bachelors' degrees were employed in such occupations, compared to $59 \%$ of the Canadian born (2003). For women, the figures were $28 \%$ and $57 \%$ respectively. The gaps were similar for those with postgraduate degrees. Reitz also shows that the representation of immigrants in knowledge occupations was lower in 1996 than it was in 1981, despite the higher education levels of immigrants (2003).

Not surprisingly, with the drop in entry earnings, rise in unemployment and concentration in low-skilled jobs with lower wages, there has been a growing incidence of poverty or low-income among recent immigrants with a university education. A study by Picot, Hou and Coulombe shows that skilled class immigrants arriving in the early 2000 s were more likely to have a low income and be in a chronic low-income situation than those entering in the family class (2007). Low-income is defined as family income below $50 \%$ of the median income of the population. As the researchers explain, "the small advantage that the university educated entering immigrants had over, say, the high school educated in the early 1990 s had largely disappeared by 2000 , as the number of 
highly educated rose" (p.4). Among immigrants classified as chronically poor, 13\% had degrees in the 1990 s while this figure soared to $41 \%$ in the $2000 \mathrm{~s}$.

The data on earnings, unemployment rates, occupational representation and incidence of low-income present a very disturbing statistical picture of the economic integration of skilled immigrants. What was seen as a worrisome trend developing in the course of the 1990s has now been recognized as a chronic problem. The bitter irony here is of course that Canada is succeeding in attracting the highly educated immigrants it seeks to respond to skills shortages and fuel economic growth, and yet failing to plug these imported knowledge workers into suitable knowledge occupations. Therefore, the country's economic growth would appear to be limited as long as this situation persists.

Poor outcomes of the highly skilled have been a Government concern for some time. An Applied Research paper published by Human Resources and Skills Development Canada in 2001 expressed dismay and apprehension at the economic failures displayed in the 1990s of principal applicants "selected for their skills... with higher levels of education and knowledge of official languages" (HRSDC, 2001). More recently, in a presentation on the topic of policy trends and challenges in immigration in November of 2008, the Director General of Research and Evaluation for Citizenship and Immigration Canada identified the poor economic outcomes of highly educated immigrants as one of the top policy concerns (Ruddick, 2008a).

The poor outcomes threaten Canada's ongoing ability to attract skilled workers because it is now developing a reputation as an environment inhospitable to immigrants. As discussed previously, Canada is keenly aware of the competition for global talent that it faces, particularly from Australia, where labour market outcomes for skilled immigrants have been very positive over the past decade (Hawthorne, 2007). Indeed, 
Canada recently commissioned a study of the Australian system to determine how it might emulate its success (Hawthorne, 2006). Also at issue is the incidence of immigrants taking their skills elsewhere, that is, either returning to their country of origin or moving on to a more economically favourable environment, such as the United States. Recent presentations on the topic by Citizenship and Immigration Canada officials reflect the fact that this is a concern (Ruddick, 2008b).

\section{Barriers for skilled immigrants in the labour market}

The barriers and challenges that skilled immigrants actually encounter in trying to access the job market are well-known based on a long list of studies which include surveys and interviews with immigrants themselves, service-providers and employers (Alboim and McIsaac, 2007; Brouwer, 1999; Lochhead, 2003; Lochhead and Mackenzie, 2005; Lopes and Poisson, 2004; Progress Career Planning Institute, 2009; Statistics Canada, 2005; Schellenberg and Maheux, 2007; Teelucksingh and Galabuzi, 2005; Wayland, 2006; Weiner, 2008). The barriers are complex and many, but they involve the following main issues: lack of recognition of foreign credentials and experience, lack of Canadian experience, insufficient official language ability, current hiring practices and newcomers' lack of social networks, lack of information regarding employment, negative employer attitudes and discrimination.

Skilled immigrants fall into one of two streams, those intending to work in the regulated and non-regulated occupations. The former group are compelled to obtain a license before they can work. This is due to the fact that certain occupations have been deemed as requiring legal regulation in order to maintain specified standards to protect the health and safety of the population (Mata, 1999). Regulation is a provincial 
responsibility which governments have in turn delegated to independent professional regulatory bodies and skilled trades. The licensing process is thus specific to each profession in each province. It inevitably involves the assessment of academic credentials, professional training and work experience. The passing of certification examinations is also a common requirement. Immigrants applying to the regulated professions experience the above barriers in a particular way relative to the licensing process, while those in non-regulated occupations deal essentially with employers. Since gaining licensure does not guarantee a job, applicants in the regulated professions are likely to face the problems encountered by those in the non-regulated occupations when they actually apply for employment (Reitz, 2005).

The evaluation of credentials constitutes a serious problem for both streams. Credential assessments for licensing are undertaken either by the regulatory bodies themselves or third-party assessment agencies. Individuals applying to non-regulated occupations are advised to have their credentials assessed by the agencies, and educational institutions provide the service as well. Frequently, however, assessment results in incomplete recognition or rejection of credentials. The Longitudinal Survey of Immigrants to Canada for 2001 showed that among newcomers who had their credentials assessed, only $54 \%$ had them fully accepted (Statistics Canada, 2003b). 22\% had them partially accepted, $13 \%$ had them rejected and $15 \%$ were still waiting for the results. When credentials are not accepted, applicants cannot obtain licensure or work in their field at their former level without retraining. This may entail taking a few courses to reach equivalency, or redoing an entire program. The time and cost involved is often prohibitive, particularly when individuals need to start earning a wage immediately to support their family. Credential assessment has, until recently, only been possible once 
the individual arrives in Canada and therefore lower assessment comes as a complete surprise.

There is currently no standardized approach to credential assessment and the different service providers use different methods which produce different results. This complicates the process for immigrants, affecting the amount of retraining for which they need to plan. It also calls the value of the assessments into question in the eyes of employers (Alboim, Finnie and Meng, 2005). The problem stems in part from the proliferation of institutions from which applicants have been presenting credentials over the past decades with the expansion of immigrant source countries, as well as the insufficient means on the part of assessors to accurately evaluate the calibre of curricula and training of all such institutions and the programs they offer (Hawthorne, 2007). This also gives way to the problem of what Mata refers to as 'statistical discrimination': in the absence of complete information, assessors will deliver an unfavourable assessment rather than take a risk that the credential does not meet standards (1999).

Non-recognition of credentials also occurs at the hands of employers. When an employer is presented with an application bearing credentials from a foreign institution, they may lack the capacity to understand their relative value. Reitz relates that "when employers respond to information about the job-relevant skills presented by applicants, they are actually relying on a fairly elaborate set of institutional supports which may not work as effectively when the applicants are skilled immigrants" $(2005, \mathrm{p} .5)$. Therefore, if employers do not recognize an educational institution, they have no reference point or framework within which to understand the productive value of the credential. In a survey of 2,091 Canadian employers undertaken by the Public Policy Forum in 2004, 52\% of respondents reported having difficulties assessing foreign credentials (Lopes and Poisson, 
2004). Inevitably, applicants with credentials from unfamiliar institutions are passed over in favor of applicants with credentials from familiar ones.

A number of studies have shown that foreign work experience is almost completely discounted in the Canadian labour market.(Alboim, Finnie and Meng, 2005; Aydemir and Skuterud, 2004; Green and Worswick, 2003; Schaafsma and Sweetman, 2001). Instead, employers often require Canadian experience in order to consider an application. The Longitudinal Survey of Immigrants to Canada found that, after four years in the country, $50 \%$ of newcomers reported that the employers they encountered desired Canadian experience (Schellenberg and Maheux, 2007). Hiring immigrants can be considered risky for employers because they are not able to access recommendations from previous employers as they are with native born applicants (Reitz, 2005). Canadian experience thus provides assurance that applicants have the appropriate skill sets and competencies, including cultural competence, to function in the local context. For licensure, many professions require applicants to work for a given period of time in their field within Canada in order to demonstrate knowledge of codes and standards specific to the Canadian work environment (Ontario Office of the Fairness Commissioner, 2008). However, Canadian experience is repeatedly referred to as a 'Catch-22' problem, because immigrants cannot obtain a job without Canadian experience, and are unable to acquire Canadian experience without a job.

Both employers and immigrants themselves have recognized that newcomers lack the social networks that are key to finding employment (Progress Career Planning Institute, 2009; Schellenberg and Maheux, 2007). A study by Liu shows the use of informal networks consisting of referrals from friends, colleagues and other employees is the preferred mode of hiring among Canadian employers (2007). An estimated $80 \%$ of 
positions are not advertised to the public, the so-called "hidden job market", and are filled through these networks. Building social networks takes time, however, and newcomers have low social capital and a low degree of social engagement because they have not resided in a Canadian community for any substantial period. Moreover, many of the jobs advertised to the public are filled by recruiting agencies who are paid to find the best candidate with the greatest likelihood of retention. Newcomer job seekers are usually immediately disqualified because of the risk factor attached to their lack of local work experience and references (Liu 2007). In large part, therefore, current hiring practices disadvantage newcomers. They are excluded from the channels through which employers fill positions.

While the Longitudinal Survey of Immigrants to Canada (2005) rated insufficient language proficiency as the third greatest barrier encountered in the labour market, it was identified as the main reason for not hiring newcomers in three separate surveys of employers (Lochhead, 2003; Lopes and Poisson, 2004; Progress Career Planning Institute, 2009). The TOEFL and IELTS tests have been used as the measure of official language ability for points-assessment, but there is a discrepancy between the knowledge levels reflected in these standardized tests and the fluency required in the workplace. When immigrants from non-English or -French-speaking countries arrive in Canada, they often do not possess the technical proficiency expected by employers and required to pass certification examinations. While the emphasis on literacy and language skills has increased in the current knowledge economy, it is recognized that opportunities for advanced and occupation-specific language training are lacking in Canada (Alboim and McIsaac, 2007; Brouwer, 1999; TRIEC, 2006; Wayland, 2006; Weiner, 2008).

A lack of clear and accurate information on issues relating to employment poses 
another major problem. Many immigrants have reported having difficulty accessing sufficient and clear information regarding licensing requirements before arrival. For example, among immigrants arriving in Ontario between 1994 and 1999 and intending to work in a regulated profession, only $56 \%$ were aware of the steps involved in obtaining a license (Ontario Ministry of Training, Colleges and Universities, 2002). In most cases, the process is actually complex, time-consuming and costly, and immigrants are caught off guard. They have not planned and allocated their financial resources appropriately and this often forces them to abandon the process and take up jobs below their skill level. The result is the same for the reported lack of information on credential assessment. Immigrants are frequently unaware of its necessity and they often do not have the proper documentation. If their credentials are discounted, they are also often not prepared for the consequences. Newcomers similarly report lacking information before they arrive regarding what jobs are in demand and where they exist (Wayland, 2006). As a result, they may come at a time or settle in an area where their prospects for working in their field are very poor, with consequent poor economic outcomes.

Finally, discrimination is another substantial barrier to labour market integration reported by immigrants. Whether on the basis of race, ethnicity or immigrant status, it can be blatant or subtle, and manifest itself in the other barriers. Two studies have shown that some employers equate the presence of an accent or lack of perfect fluency with incompetence, rejecting the applicant under the banner of 'language barriers' (MacDougall, 2007; Scassa, 1994). Lack of Canadian experience can be used as a basis for exclusion due to otherness if it is deemed the individuals cannot 'fit in' to the workplace (Weiner, 2008). The value of foreign credentials is also often filtered through racial attitudes. In a study by Dietz et al., subjects assigned a lower value to the foreign 
credentials of black immigrants than those of white immigrants when they were not accredited (2009).

Dietz et al. explain that when a non-prejudicial justification is available for not hiring an immigrant, such as unfamiliar or uncertain credentials, lack of Canadian experience or language barriers, employers or regulators often use it (2009). This may even be in spite of conscious efforts to remain unbiased. As Teelucksingh and Galabuzi (2005) and Liu (2007) describe, there is a pervasive image of immigrants as inferior, needing help and struggling to be integrated into the mainstream. This image has been historically constructed and reinforced by the mass media. In short, immigrants are perceived as deficits to society rather than assets and this plays on the consciousness of those making employment decisions.

The negative perception of immigrants combines with racialized attitudes to strike visible minorities twice as hard. The statistical evidence for this is profound, for while immigrants do poorly in economic terms compared to the native born as demonstrated above, research shows that visible minorities do worse. Studies by both Pendakur and Pendakur (1998) and $\mathrm{Li}(2000)$ found that visible minority immigrant men earned between 14 and $20 \%$ less than white immigrant men. Teelucksingh and Galabuzi found evidence that racialized immigrants have higher unemployment rates and higher rates of representation in low income occupations compared to their non-racialized counterparts (2005). In addition, Alboim, Finnie and Meng showed that non-white immigrants receive returns that are one third less than those of white immigrants (2005). And finally, Ferrer and Riddell have demonstrated that the foreign work experience of Asians is substantially discounted, while that of Europeans is only somewhat discounted (2004). 


\section{Disjuncture between federal selection policy and the labour market}

The barriers and resulting poor economic outcomes that skilled immigrants experience reveal a disjuncture between federal selection policy and the labour market. While the federal state controls the selection of immigrants to Canada and its priority is to recruit the highly-skilled, access to the job market is controlled by employers and the professional regulatory bodies at the provincial level. The principles that guide the selection of immigrants, however, are not supported in practice in the labour market.

Skilled worker principal applicants are, of course, assessed according to the Points System which is a human capital model of selection whereby great weight has been allocated to education, experience and official language skills. This has been the case since the system's inception in 1967, but in the mid-1990s, emphasis on these characteristics was bolstered when they were accorded up to 57 out of 107 points. This increased to a further 70 out of 100 points in 2002, when the new Immigration and Refugee Protection Act was introduced (Canada Gazette, 2002). Human capital theory is the guiding perspective, according to which education, skills and experience represent an investment that is expected to bring a return in the form of earnings in the labour market (Becker, 1993). The higher the investment, the higher the return. Immigrants to Canada are therefore selected based on the productive value assigned to their human capital. The governing principle has been 'the more human capital, the better, because education and skills are valuable in the knowledge economy'.

The education, skills and experience of applicants are not evaluated in any way, however, to determine fit with the Canadian labour market. Up until the changes introduced with the passing of Bill C-50 in June 2008, all fields of educational qualification were valued equally, regardless of their potential practical application in the 
Canadian context and their relationship to demand. This is in contrast to Australia's point system, where greater weight is given to the field of educational qualification and to qualifications related to specific, rather than generic, professional fields (Hawthorne, 2008). Bill C-50 has recently limited the processing of skilled worker applications to those matching a list of thirty-eight occupations deemed to be in demand in Canada. This was initiated only in November 2008, however, and applications received prior to February 2008 will continue to be processed according to the former criteria. Prior to 2002, the Canadian system did allocate a few points to the applicant's field of training relative to occupations in demand, but it has always been possible to pass without these points.

In the selection process, all credentials are also accepted at face value and valued equally regardless of where they were obtained. Documentation is required for the application, but contrary to Australia, where credentials are assessed prior to selection, no assessment is undertaken as part of the processing of applications in Canada. This is in spite of the fact that credential assessment is one of the first steps to finding employment and that there are vast discrepancies in the level of equivalency assigned to the different degrees and programs of global candidates. The Points System also allocates points for work experience even though numerous studies have shown employers and regulatory bodies do not value it. And with respect to language skills, the maximum number of points awarded and the scoring systems for accepted tests do not reflect the fluency required by regulatory bodies and employers.

Canada's selection model, however, assumes that all foreign human capital is on par with and perfectly transferable to the Canadian labour market context. As Li elaborates, it supposes "a perfect competitive system in which immigrants and native 
born citizens are rewarded in the same way in the labour market except for differences in human capital and marketable skills" (2003, p.294). Indeed, the Applied Research paper released by Human Resources and Skills Development Canada in 2001 expresses the government's expectation that points-assessed immigrants will reach earnings parity with the Canadian born shortly after arrival because of the very fact that they were chosen for their human capital (HRSDC, 2001). In reality, the productive value of immigrants' human capital is determined by credential assessment agencies, professional associations and, most importantly, employers. As we have seen, a host of factors come into play in the evaluation of an applicant's qualifications. Their quality may be lower, they may not be suited to the Canadian economy, Canadian professional associations and employers may lack the ability to properly evaluate them, less proficient language skills on the part of newcomers may prevent their full use, and employers and associations hold negative attitudes towards immigrants and discriminate on the basis of race and ethnicity.

A serious gap in expectations has been created as a result of the disjuncture between selection and the realities of the labour market. Earning the requisite number of points to 'pass' the points system is equated with a 'stamp of approval' on the applicant's qualifications. The message conveyed is that their skills and experience are valuable and that the labour market is waiting for them. Man quotes one illustrative comment from a woman from Mainland China: "We thought that if the Immigration Department accepted us as 'other independent' [skilled workers] class immigrants, and we got in with high points because of our profession and education, we shouldn't have difficulty in getting jobs. So it's an expectation problem" (2004, p.144). This gap results in the severe disappointment, dissatisfaction and marginalization of skilled immigrants. It contributes to Canada's growing reputation as a country inhospitable to newcomers as immigrants 
share their experiences with each other and their networks abroad. Websites such as "Not Canada" (www.notcanada.com) provide a forum for newcomers to air their discontents with the Canadian immigration program and a common theme is skilled worker immigrants who feel they have been blindsided by the Points System. Research by Aydemir and Robinson shows that beween 1980 and 2000, 40\% of immigrants admitted under the skilled worker or business class left Canada within ten years of arrival (2006). In the current global climate of increasing competition for skills, it will become easier for the highly educated to pick up and leave Canada for a more receptive environment or to return to their home country.

\section{Pre-migration preparation}

Between 2003 and 2004, the federal government began to focus more intently on improving the labour market outcomes of international skilled workers with the development of the Foreign Credentials Recognition Program (HRSDC, 2007).

Strengthening the foreign credential assessment and recognition processes was viewed as the most important way to begin to address problems with labour market integration. Shortly thereafter, in 2005 , the impetus to facilitate such integration grew with the introduction of the Internationally Trained Workers Initiative. For the first time, the government articulated the intent to focus on the preparation of immigrants for the labour market before they leave their home country.

Since then, several initiatives have been introduced. These initiatives consist of online and in-person provision of information, referral and path-finding services. They are driven by the notion that such tools will allow skilled immigrants to bypass some of the challenges identified and gain faster access to employment in their field. The 
initiatives include the Going to Canada Portal with its Working in Canada Guide and Working in Canada Tool; the Foreign Credentials Referral Office with its Essential Workbook for Newcomers; and the Canadian Immigration Integration Project. Each will be examined in turn in the following section.

Since 2002, researchers have increasingly been recommending the overseas preparation of skilled workers for the Canadian labour market increasingly since 2002 . Such preparation is viewed as a means to minimize the risk of the highly skilled ending up in jobs below their skill level. In a 2002 study on integrating immigrant skills into the Canadian economy, Alboim was the first to suggest that the more immigrants can begin to prepare from overseas, the greater the chances for early and successful labour market entry. She explains:

"Overseas opportunities make sense with planned immigration, as opposed to the refugee situation in which there is an urgent need to leave the home country. In the normal course, there is a waiting period between deciding to immigrate and the actual move to Canada. There can be several advantages to using this time period to begin to identify - and perhaps begin to fill - gaps between one's qualifications and Canadian requirements. First, it can be beneficial to embark upon this investigation while still in familiar surroundings and with one's network of contacts and supports. Second, it can help immigrants to 'take charge' of their future instead of passively waiting for their departure to Canada. Finally, it can shorten the time to enter a specialized field in the new country" (2002, p.18).

Recommendations from researchers for overseas actions to prepare for employment have been numerous. Many say immigrants must receive clear and authoritative information on precisely what is needed to practice one's specific occupation in each region (Alboim, 2002; Alboim and McIsaac, 2007; Lochhead and Mackenzie, 2005; Owen and Lowe, 2008; Sangster, 2001; TRIEC, 2006). Such information encompasses licensing requirements for the regulated occupations in each province and the specific programs or competencies expected for the non-regulated occupations. The need for 
information on credential assessment has also been specifically recognized, as well as accurate information on what jobs are in demand and where those jobs are located. In addition, Alboim and McIsaac (2007) and Owen and Lowe (2008) call for information or counseling on job search and résumé skills, employer expectations and cultural workplace norms. Such information would create awareness, contribute to realistic expectations and also allow individuals to take steps towards employment. In addition, it would allow immigrants to gather the kinds of documentation and evidence of previous work experience and competencies they will require, all of which is more difficult to access once they have left their home country.

Many have called for overseas access either to self-assessment tools or to assessment services for credentials and other occupational skills, including language (Alboim, Finnie and Meng, 2005; Alboim and McIsaac, 2007; Owen and Lowe, 2008; TRIEC, 2006). If skilled workers could actually conduct assessments before they depart, they could identify gaps and begin to address them. They could also, however, make informed decisions regarding whether or not to come to Canada or, alternatively, how to apportion their financial resources for retraining.

Furthermore, Alboim, Finnie and Meng (2005) and Owen and Lowe (2008) have suggested that pre-departure preparation include the initiation of the upgrading of occupational and language skills. They call for access to courses by recognized Canadian service providers either over the internet or in classes established overseas that would bridge the gap in training, thus saving time while also providing newcomers with a Canadian credential.

Finally, Alboim and McIsaac have argued that immigrants should be connected both to employers and mentors after their applications are approved (2007). The latter 
would provide crucial information on sector and workplace norms and expectations in Canada as well as opportunities for networking. Connecting approved immigrants with employers via a database of profiles would speed up entry into the labour market. All of these recommendations have been implemented to some extent in the federal initiatives.

\section{Federal government initiatives}

\subsection{Canadian Orientation Abroad}

Canadian Orientation Abroad merits consideration, for while it is not part of the recent attempts to address poor labour market outcomes, it is the original pre-migration preparation initiative. Funded through the Immigrant Settlement and Adaptation Program of Citizenship and Immigration Canada, it has been operating since 1998. It was developed on the premise that the more prepared immigrants are for Canadian society in general, the greater success they will have in settling in the country (Biles, 2008). The program thus offers in-person services to participants with a view to guiding them through the migration process in order to facilitate both social and economic integration into Canadian society. The focus is on cultural orientation and dealing with the initial demands of adaptation and settlement, as opposed to labour market integration.

The Orientation consists of a series of workshops whose length depends on immigrant class: three-day sessions for Convention Refugees, two-day sessions for family class individuals and a one-day session for Skilled Workers. A single-day session was also recently introduced for Temporary Live-In Caregivers. With the exception of the Caregivers, all participants have been approved for permanent residency. Spaces are limited, however, and priority is given to refugees. Locations of session offerings change and are determined according to perceived demand by Canadian missions abroad. Since 
the primary focus is on refugees, the locations have mostly coincided with high numbers of this group. Thus far, this has included Vietnam, Kenya, Djibouti, Egypt, Uganda, Tanzania and Ethiopia, Pakistan, Iran, Syria, Jordan, Lebanon, the Balkans and the Philippines (CIC, 2005).

Sessions are usually delivered in the participants' native language and topics include an introduction to Canada, the settling-in period, employment, rights and responsibilities, climate, finding a place to live, living in a multicultural society, the cost of living, family life, education, communications and adaptation to Canada (CIC, 2005). There is only one section in any given session dealing with employment and the information is very general. In an evaluation of the program conducted in 2005 , Skilled Worker participants stated that the session's content did not provide them with enough information relevant to the needs of their category. More information on employment was requested, specifically on the following: the process of looking for work, transferability of professional and other credentials, regional unemployment rates (especially by occupation), expectations regarding employability in their profession and economic conditions and employment specific to their regions of destination (CIC, 2005). The orientation curriculum has not been altered, however.

\subsection{Going to Canada Portal}

When the Internationally Trained Workers Initiative was introduced in 2005 and the government decided to provide immigrants with information prior to departure to prepare them for the labour market, the Going to Canada Portal was designated as the vehicle for that information (HRSDC, 2005a). Taking over the existing Going to Canada website, development of the portal began in the same year in partnership between 
Citizenship and Immigration Canada and Human Resources and Skills Development Canada, and in collaboration with the provincial and territorial governments. The portal is designed as a one-stop online resource and contains a broad range of information on Canada's labour market, educational system, culture, and regions and communities. In the interest of making the material available on the site comprehensive and authoritative, an effort has been made to coordinate information among the different levels of government, settlement service organizations, learning and educational associations, employers, occupational associations, and organizations that assess foreign credentials (HRSDC, 2005b). The portal's key target audience is skilled workers and, as one media release explains, it was developed especially because "the Internet is increasingly the preferred source of information for many of the highly skilled immigrants Canada is trying to attract" (HRSDC, 2005b). It also aims, however, to address the needs of international students and temporary workers and therefore contains information applicable to their circumstances as well.

The site is organized into topics, including 'Immigrating', 'Visiting', 'Studying' and 'Working in Canada'. For the last, the user can access the 'Working in Canada Guide' as well as the 'Working in Canada Tool'. The Guide can be perused in an online format or downloaded and printed. It covers Canadian government and the employment system, choosing a place to live and work, important documents, finding a job, challenges to working in Canada, taxes and benefits, worker rights and a warning about the use of immigration consultants. Most of this material, however, is treated in the more focused Working in Canada Tool. The information in the Guide is terse and general, although it does raise awareness regarding all the issues the user needs to consider in attempting to transfer to the Canadian job market, especially credential and skills 
assessment.

Of note is the Guide's presentation of the four major challenges that immigrants face in the Canadian labour market articulated in the Longitudinal Survey of Immigrants to Canada. Work experience, labour market contacts and networking, foreign credential recognition and communication skills are identified as posing problems for newcomers. Although the Guide highlights the fact that newcomers do indeed experience these barriers raises awareness, the material is far too brief to give users any firm grasp of the issues. For example, the challenge of work experience is summed up in the following way: "Experience in a Canadian workplace may be a requirement or an employer preference, in both regulated and non-regulated occupations. It is useful for newcomers to present experience they have gained in another country as valuable to Canadian employers." This conveys no understanding of why Canadian experience is required or preferred and the second sentence gives the impression that employers will indeed accept foreign experience at face value. The user needs to be apprised of the factors which lead to the discounting of such experience. Similarly, the section on communication skills only contains the attestation that 'official language ability is important in finding a job'. That importance requires qualification so the user can adequately plan for the necessary training. More extensive information on the challenges is required. The Longitudinal Survey of Immigrants to Canada provides such detailed information, and a link to the study is provided, but it is identified only by the caption 'Statistics Canada'. This should constitute recommended reading and users should be explicitly referred to the link.

\subsection{Working in Canada Tool}

The Working in Canada Tool has been available since November 2007 on the 
Going to Canada Portal. It allows the user to type in their occupation and intended destination in order to produce a report with specific labour market information. It is therefore more focused than the Working in Guide in its information, path-finding and referral services and it has a greater capacity to help prospective immigrants make wellinformed decisions about where to live and work before leaving because it allows them to compare different jobs and prospects across the country.

The Tool uses the National Occupational Classification system which groups different jobs into occupational categories assigned a four-digit code. The Report first tells the user whether their occupation is regulated or not and what that signifies. An explanation of the importance of credentials and how assessment pertains to each type of occupation immediately follows, alerting the user both to the fact that assessment is critical and that it will take time and cost money. If the occupation entered is regulated, a link to the appropriate regulator is given, along with links for further information, including the relevant provincial website.

The remainder of the Report's information is organized into eight sections. Apart from the section on 'language assessment', all of the material is derived from the federal government's Labour Market Information resource which provides data on national outlooks and work trends and is updated as information becomes available. 'Main duties' and 'jobs and skills requirements' provide detailed occupation-specific information, with extensive examples supplied for each skill. 'Wages' follows where average, low and high wages are compared across the different regions of each province as well as to the national picture. 'Outlook and prospects' provides a rating of 'limited', 'fair' or 'good' for each provincial region along with a description of trends.

The section on 'job opportunities' is limited to the current openings in the federal 
Job Bank, although there are links to other online job search sites provided. There is a note on using networking as another search strategy accompanied by further links, but these do not lead to any practical information, only the suggestion that the user contact settlement agencies to learn more. This is inadequate. Research shows that less than $10 \%$ of jobs are actually filled through the Internet and the overwhelming majority through networking. More substantive information should be provided to raise awareness about this aspect of the labour market and users should be able to connect to topical resources so they can work on developing contacts from abroad.

Information on all the local institutions which offer relevant programs is contained in 'education and training'. For many occupations, however, this section contains no information. 'Associations and unions' contains a list of relevant region-specific links which are presented as additional information resources. The 'further information' section contains links to provincial portals and other federal sites. Finally, 'language assessment' contains some frank statements about the importance of being able to communicate well in English or French in order to find and retain employment. In contrast to the corresponding section in the Working in Canada Guide, here the user is alerted to a distinction between knowing the language and being able to actually work in the language. Information on improving and getting one's skills assessed follows, but the programs and services described immediately after can only be undertaken once in Canada, thus providing limited assistance to the user.

The Tool certainly contains some very valuable information and referral provisions. With the data and links provided, users destined for regulated professions can eventually determine the credential recognition and language assessment processes that apply to their occupation, whether and how to initiate the processes from overseas, and who to 
contact for information if upgrading is required. However, the Tool is not as helpful for those applying to the non-regulated professions. There are no instructions on how to deal with credential assessment and language assessment since it is not required. Given that the Tool is intended to be occupation-specific, it should include some direction on what assessments are preferred in the different sectors.

There are other limitations. Working within the Tool itself, users are left to their own devices in determining the steps to be taken to become job ready. The appropriate information and referrals are available, but it is up to the user to make sense of what to do with them and this is a complicated task. Also, since the Tool operates at the occupational level, there is no specific information given for different jobs within a given occupation. For example, the occupation 'social worker', includes five jobs: social worker, coordinator of social work, social work supervisor, medical social worker, psychiatric social worker. The training, duties, skills, wages and prospects of all five vary significantly, but they are classified together. In addition, focus group participants asked to evaluate the Tool before it was launched pointed out that it lacks desired information on the following topics: cost of living in different regions, typical benefits offered by employers, different forms of employment (ex. full-time, part-time, contract, casual), how to search for a job and workplace norms and culture. (EKOS, 2007) These deficiencies have yet to be addressed.

Furthermore, there is no link or reference provided to the various bridge training programs that are offered by educational institutions and employment or settlement organizations in cities across the country. The existence of such a program in one's sector and destination city is a critical piece of information for the planning process and needs to be included in the Tool. Currently, the Ontario Ministry of Citizenship and 
Immigration provides the only list of bridge programs arranged by sector for any of the provinces (http://www.citizenship.gov.on.ca/english/working/experience/).

\subsection{Foreign Credentials Referral Office, Essential Workbook}

The Foreign Credential Referral Office (FCRO) was opened in May of 2007 under the aegis of Citizenship and Immigration Canada as part of the new impetus to improve the labour market outcomes of the foreign-trained by intervening both before and after they arrive in the country. The FCRO was conceived as a centralized office dispensing practical information, path-finding and referral services in relation to the Canadian labour market and credential recognition process. Its goal is to expedite skilled immigrants' employment at a level matching their skills and experience. The Office's services are offered over the phone through a toll-free number, in-person at the Service Canada centres, and online through its website, www.credentials.gc.ca. Individuals overseas have access to the website alone.

The website includes a roadmap for employers on hiring and retaining internationally trained professionals and a link to the Working in Canada section of the Going to Canada Portal, but its main feature is the Essential Workbook for Newcomers. This was issued early in 2009 and is intended to be printed out and used as a working document in conjunction with the Report from the Working in Canada Tool. It provides step-by-step instructions on what users need to do to look for and obtain work and how to go about accomplishing this while still overseas. The workbook furnishes the direction lacking in the Tool. There are five main sections, followed by a glossary of terms and a list of important links.

The first section, Living in Canada, identifies the steps to take to be informed about 
a destination and deal with initial settlement issues. Section two emphasizes the importance of official language ability and consequently of determining whether more language training is needed. Directions are provided regarding how to conduct an assessment from abroad and how to find training prior to coming to Canada, should it be necessary. This is important, for both the Working in Canada Guide and Working in Canada Tool only reference training opportunities available once the user has arrived in Canada. Here, the user is also alerted to the fact that proof of language ability may be required for one's intended job, with directives on how to find out and then how to obtain it.

The third section, Finding a Job in Canada, is the most extensive. It begins by prompting the user to identify their occupational title and the job names that apply to them. Using the Working in Canada Tool, they are asked to determine whether the occupation is regulated and whether certification, licensing or registration is required. If so, the user is prompted to identify and record what the requirements are. If they do not currently meet the requirements, they must determine the steps needed, including the cost and time necessary for each. The user is then requested to fill out a schedule with a sequence of actions for meeting their occupational requirements.

The following six steps coincide with the topics in the Working in Canada Tool: 'main duties', ‘jobs and skills requirements', 'wages', 'outlook and prospects', ‘job opportunities' and 'education and training'. The questions asked oblige the user to review the elements of each section carefully in order to ensure that they are aware of relevant information concerning their particular occupation and intended region, and that they consider whether they have all the necessary qualifications. The job opportunities step directs them to track down and record specific prospects. 
Further steps ask the user to investigate other jobs related to their field or skills, education and abilities in case it takes a long time to become licensed, or in case they need other employment options. The latter case is very gingerly worded so as not to alarm the prospective immigrant regarding the possibility they may realistically not be able to work in their intended occupation. They are prompted to make a list of other job possibilities and the actions, time and cost required to pursue those other avenues. To round out the steps, there are directions on preparing a résumé and cover letter, preparing for an interview, how volunteering can help one find a job and starting one's own business.

The following section provides instructions on how to identify and locate the workrelated documents the user will need for their employment search before they leave their country. This includes documents that verify educational record, professional training and work experience with directions for mailing, translating and what to do in the case of missing documents. This is a crucial step, for the documentation process for both credential assessment and licensing is extremely involved and the complication multiplies if everything needs to be gathered from Canada. Finally, the Education and Academic Credentials section explains the issue of equivalency and the need for credential assessment. Since many assessments can now be done from abroad, the user must determine whether this applies to their occupation and what the cost and time involved will be. If assessment reveals that upgrading is required, there is a prompt to search for a course of study with the required training in the destination area.

This Workbook, in conjunction with the Working in Canada Report, has a great deal of merit. It creates awareness concerning all the essential issues surrounding employment, particularly the fact that credential assessment is a necessity and that, along 
with foreign work experience, one's credentials may not be accepted by regulators or employers. Users learn that they may have to retrain and that they may not be able to work in their profession. The Workbook provides them with directions to learn precisely what is needed to practice one's occupation and allows them to lay out a step-by-step plan for finding work. This includes approximating the cost and time involved for the various required processes. The workbook thus permits users to reasonably prepare for the Canadian labour market and it certainly contributes to the development of realistic expectations. The very first page contains the warning that being accepted to come to Canada does not guarantee employment.

Other caveats, however, are not enunciated strongly enough or are lacking. While alerting the user to the importance of official language proficiency, the relevant section does not convey the intensity of the barrier posed by insufficient fluency, and it is silent regarding the well-reported discrepancy between test scores and the communication facility required by employers. Numerous studies have identified official language proficiency as the most important determinant of successful labour market integration and it is therefore crucial to impress its significance upon prospective immigrants at every point of contact. There is no mention, either, of discrimination against newcomers or employer hiring practices and the crucial nature of networking. These omissions are no doubt a result of an effort to strike a balance between responsibly alerting prospective immigrants to the challenges they will face, and discouraging them from choosing Canada as an immigration destination.

Collectively, these new online resources provide a wealth of employment information, referral and path-finding. They certainly serve to introduce users to the issues surrounding the need for registration in the regulated professions and the facts of 
credential evaluation and language assessment. However, these online resources are very involved and the process of following all the links quickly becomes overwhelming. The Working in Canada Tool provides some occupation-specific information and the Workbook provides direction on how to use it, but it is necessary for the user to visit and scour so many other sites in order to pin down all the information specific to their profession and destination.

If the user does not possess strong English or French skills and sharp online navigation skills, it is questionable to what extent they can actually benefit from the online resources without assistance. The number of immigrants to Canada from nonEnglish- or French-speaking-background countries has been increasing. While 25\% of immigrants with degrees came from English-speaking source countries prior to 1991, this was the case for only 7\% between 1991 and 1996 and 5\% between 1996 and 2001 (Hawthorne, 2006). The 2006 Census showed that $70.2 \%$ of the foreign-born population had a mother tongue other than English or French, up from 67.5\% in 2001 (Statistics Canada, 2006b). Given these statistics, how many prospective immigrants can in fact fully understand and interpret the online information in all its complexity on their own? In addition, while the development of these online resources has been guided by the assumption that highly skilled prospective immigrants are entirely internet-savvy, the proportion for which that assumption actually holds true is unclear (HRSDC, 2005b). For example, in an evaluation of the Working in Canada Tool, skilled worker focus group participants revealed that they found the website overwhelming (EKOS, 2007).

Undoubtedly a number of skilled worker class immigrants do have the internet and language skills necessary to navigate and make sense of the information on the websites, but the number may not be as high as the site developers think. 
The ability of prospective skilled immigrants to take advantage of the information and resources on these sites is also affected by issues of accessibility. The focus group participants in the evaluation of the Working in Canada Tool pointed to the fact that, in some countries, access to the internet is limited (EKOS, 2007). Others may have internet access, but connection speed may be slow, for example. In this case, the time required to load pages and navigate all the links may curtail one's ability to retrieve all the necessary information.

Immigration consultants have stepped in, offering services to help clients navigate labour market preparation precisely because of its complexity. For a fee, a number of consultants based in countries like China, India and Pakistan offer to undertake a range of processes for labour market entry on behalf of their clients. For example, Wesley Immigration Consultants in Hyderabad, India, offer to perform the following, specifically for immigration to Canada: provide information on licensing and registration requirements, undertake the credential recognition process on behalf of the client, assist with the licensing process, locate occupation-specific upgrading programs and undertake a job search to help clients find employment before they leave India (www.wesleyimmigration.com). The difficulty involved in steering a course through all the available information on labour market preparation has created a market for fee for service assistance.

\subsection{Foreign Credential Referral Office, Canadian Immigration Integration Project}

The Canadian Immigration Integration Project (CIIP) was developed as another pre-migration strategy to improve the labour market integration of skilled immigrants. The Project offers in-person services to Skilled Worker Principal Applicants and their 
spouses. As with the online resources, the Project's goal is to give participants a more realistic understanding of the opportunities and challenges of the Canadian labour market, allow them to make better informed decisions about immigrating and where they choose to settle, and better equip them for entry into the labour market (Murray, 2007b). In addition to information and referral, though, participants also receive practical assistance, advice and guidance.

The CIIP was launched as a pilot project in January 2007, yet the idea emerged in 2004 when the Foreign Credential Recognition Program came to light with the federal government's devotion of greater resources to addressing the poor outcomes of the highly skilled. CIIP is funded through the Foreign Credential Recognition Office under Human Resources and Skills Development Canada in partnership with Citizenship and Immigration Canada. It is delivered by the Association of Canadian Community Colleges, an Ottawa-based organization which represents colleges and institutes to government, business and industry. Such a third-party delivery structure is akin to that of the Canadian Orientation Abroad, which is itself administered by the International Organization for Migration, an intergovernmental agency based in Geneva.

The Project is offered in China, India and the Philippines, the three greatest source countries of Skilled Worker immigration to Canada. Initially, services were available only in Guangzhou, New Delhi and Manila. In the Fall of 2007, they were added on a rotational basis in the states of Gujarat and Punjab in India, and in Beijing and Shanghai in China in order to respond to the high numbers of skilled immigrants from those areas (CIC, 2008A).

In each country, services are offered out of a field office which has a Canadian manager and four local counselors. When Skilled Worker applicants from the three 
respective countries receive notice that they have reached the final stage of the immigration process when health and background checks are undertaken, they are also informed about the Project and invited to participate on a voluntary basis. Citizenship and Immigration Canada staff and officers have also been asked to encourage eligible clients they encounter to participate (Murray, 2007a).

Services, which are free of charge, consist of a single-day group labour market information session and an individual counseling session for which participants return the following day. The group information sessions serve up to twenty participants and an effort is made to assemble them according to province of destination. The day is divided into five sections and the goal is to introduce participants to the mostly web-based information and resources available and provide them with some direction on how to use them on their own. In the first section, participants are given an overview of national economic trends and labour market prospects specific to their province of destination. Next, session leaders demonstrate the path-finding process for occupational requirements by presenting the various online information and resources which exist. These include the Working in Guide and Tool as well as the Essential Workbook for Newcomers. Participants are taken through a case study of both a regulated and non-regulated occupation (Murray, 2007a).

The third and fourth sections of the day deal with the opportunities and challenges immigrants face in settling and working in Canada. Session leaders explain the demographic problems Canada is facing due to a low birth rate and ageing population in order to impress upon participants the extent of labour shortages and the fact that the Canadian government is looking to immigration to fill them. The challenges newcomers encounter are subsequently discussed in the same manner as the Going to Canada Portal. 
Work experience, labour market contacts, networking, foreign credential recognition and communication skills are all outlined with general advice on addressing them through preparation. In the final section, participants are guided through the process and the existing online resources for job searching (Murray, 2007a).

The individual counseling session lasts approximately one hour. The counselor provides customized advice and guidance to help the client produce what is referred to as an 'Individual Integration Plan'. In a manner similar to the Essential Workbook for Newcomers, the counselor and client develop a list of actions necessary for labour market entry including credential assessment, language and skills testing and upgrading, licensing and job searching. Clients are referred to the appropriate regulatory bodies and service providers as well as to other employment and settlement resources or organizations that can provide additional support online or upon arrival at their destination (Murray, 2007a).

Beyond this, however, counselors are able to inform and refer their clients to sector- and occupation-specific training opportunities, apprenticeships, bridging programs and mentorships because the Project has created a network of provincial governments, education and training providers, immigrant-serving organizations and employers who offer programs for the internationally educated (ACCC, 2008b).

However, the federal online resources discussed thus far do not contain a database of such programs and clients are usually only referred by settlement organizations once they arrive in Canada. Through participation in the CIIP, therefore, clients can learn about and connect to programs they would likely never be able to find on their own while still overseas. In addition, they are given access to an online dialogue and referral system which allows them to obtain further information on such programs and to receive 
ongoing support (ACCC, 2008a).

Together, both the group and individual counseling sessions provide an opportunity for participants to focus on key information requirements, identify reliable information sources, understand and interpret information, apply new knowledge to their own situation through planning and connect to those providing support (Murray, 2007b). This is possible, of course, because the sessions are interactive and personal assistance is provided.

There are limits, however to the extent to which the CIIP can achieve its goals with its current delivery structure. For example, the accessibility of Project services is severely restricted. Services are currently only offered in three countries and, within these, only in select cities. Travel is required for those applicants who do not live in the vicinity and cost, time and scheduling issues all act as significant deterrents. If out-of-town participants wish to attend both the group session and the individual counseling session the following day, they need to make arrangements for overnight accommodation, a further deterrent. According to the Project's statistical report for 2007 and 2008, in China, the largest of the three countries, only $48 \%$ of eligible applicants were willing to travel for the services (ACCC, 2009). Even the field office's location within a city can affect attendance. The office in New Delhi was moved in 2007 precisely because it was in an area that was difficult to reach (ACCC, 2008). While the CIIP has not published the number of applicants who were eligible and thus invited to participate, there are a significant number who registered and ultimately were unable to attend. In 2007 and 2008 , out of the 5,304 approved Skilled Workers who actually registered to participate in the Project, only 3,661 finally attended (ACCC, 2009). More importantly, however, the number of individuals who received services in 2007 and 2008 amounts to only $1.8 \%$ of 
all immigrants who entered Canada under the Skilled Worker Class in those years.

Accessibility needs to be improved with services offered in a greater number of cities.

The Project services are also only made available at the final stage of the immigration process. Such a decision clearly reflects budgetary concerns and the need to limit expensive services to those who have been approved for immigration to Canada as opposed to all those who apply. However, offering the services at this late stage severely limits what participants can accomplish prior to departure. Depending on the processing time of the assessment body relevant to them, participants may or may not be able to complete the credential and language assessment process and identify gaps in education and language. There is certainly not enough time, however, to begin to address those gaps. Participants' planning and preparatory capacity is thus seriously curtailed. In fact, the Project's report for 2007 and 2008 indicates that some individuals who had registered for services left for Canada before they had the chance to attend.

In addition, participants will have already chosen their settlement destination by this point. Indeed, they are grouped together for the day-long information session on the basis of their destination location. How can they make well-informed decisions about where to settle, though, if they do not receive the information on labour market prospects and outlooks at such a late stage? The aim of preparing participants by providing the information is defeated in this case. Making the assistance available earlier in the immigration process should therefore be given serious consideration.

The brevity of the group information and individual counseling sessions also places a serious limit on the amount of instruction and guidance participants receive. As discussed above, the path-finding process for occupational requirements using the available web resources is complex and involved. In a single-day group session, 
participants receive only an introduction to these resources. While session leaders demonstrate path-finding with one example of both a regulated and non-regulated occupation, it is impossible to provide any significant level of instruction, for this is but one of a number of topics on the agenda. The only opportunity that participants have to ask questions is during the counseling session, which is limited to one hour. It would be challenging for participants to make the most of this hour if they have only been exposed to all of the issues of labour market entry for the first time the day prior. The effectiveness of the resources available would be greatly increased if participants could return to consult with counselors for on-going support. Participants will no doubt have further questions once they have had the opportunity to digest what they have been taught in the information and counseling sessions and the chance to explore the issues specific to their situation.

There is also an issue with language of service. In China, services are offered in the participant's choice of Chinese or English. In the Philippines and in India, however, they are only offered in English. Only $60 \%$ and $69 \%$ of participants respectively selfidentified as being fluent in English in those countries (ACCC, 2009). Clearly services are being offered in Chinese because Project administrators acknowledge that applicants cannot otherwise fully benefit from the information and guidance provided. However, this opportunity is not being extended to all eligible participants.

In exposing participants to all the issues involved in working in Canada, the Project is aimed at cultivating realistic expectations on the part of participants (Murray, 2007b). As with the online resources, though, the barriers faced by newcomers are not adequately represented. In the Project's promotional video, which shows excerpts from a group session in India, the session leader is shown affirming that participants' foreign work 
experience is valued by Canadian employers. It seems this is done in order to imbue participants with a sense of confidence regarding their prospects for work and to temper the positive with the negative in the presentation of the opportunities and challenges to be faced in Canada. However, there is a limit to how prepared participants can become and how realistic their expectations can be if the significance of challenges such as nonrecognition of foreign work experience is not adequately conveyed. The counselors cannot offer any explicit information on the challenges themselves because they are local and have no personal experience with the Canadian labour market. This also raises the question of how effective they can be in providing advice and guidance when they have no practical knowledge of the situation in Canada.

The Project has yet to be evaluated by the federal government but Project administrators have collected their own feedback on the services from participants. Upwards of $90 \%$ of participants said the services were very useful, that their expectations had changed as a result of the services and that they had contributed to planned actions for labour market integration. However, in comparison to these marks in the $90^{\text {th }}$ percentile, only $76 \%$ of participants strongly agreed that their understanding of the Canadian labour market had improved as a result of participating. Thus, $24 \%$ of participants did not receive all the information or assistance they felt they needed (ACCC, 2009). It is important to note, however, that the feedback was collected before participants had set foot in Canada and come face to face with the labour market. While Project administrators are trying to establish links with different organizations for tracking and exploring the possibility of using survey tools such as the Longitudinal Survey of Immigrants to Canada through Statistics Canada, there is currently no means of measuring the impact that Project services have on labour market outcomes (Murray, 
2007a).

As a pilot project, the Canadian Immigration Integration Project is slated to run until October 2010. The federal government very recently issued a call for proposals for the delivery of the same in-person services to commence when the project ends, with no interruption in service (FCRO, 2009). London, England, will be added as a fourth service location at that time. It is unclear whether the involvement of the Association of Canadian Community Colleges will continue, or whether there will be multiple service providers. What is clear, however, is that this type of in-person service is a growing priority for the federal government. The Foreign Credentials Referral Office has explained that, with the online resources now established, it will devote its energy almost entirely to the overseas initiatives.

\section{The role of the regulated bodies in pre-migration preparation}

Even if immigrants are able to take maximum advantage of the available online resources and in-person services, it is important to note that how much they can actually prepare and how far they can proceed on the path to employment from overseas are ultimately determined by how accessible the regulatory bodies and employers have made registration and employment to the internationally trained. Regulatory bodies and employers are, of course, the gatekeepers for employment in the regulated and nonregulated occupations and they need to have taken a pro-active approach to make information and processes available from abroad. What initiatives they have taken often reflects how open they are to the internationally trained in general.

An entirely pro-active approach on the part of regulatory bodies would involve the following initiatives: posting all of the registration requirements clearly on the regulatory 
body's website; articulating a pathway to licensure specifically for the internationally trained with step-by-step instructions and an indication of the time and cost involved in each step; providing for credential and language assessment to be conducted from overseas in addition to the writing of licensing examinations. It is also key that there be systems in place to help the internationally trained meet registration requirements which are clearly explained in the articulation of the pathways to licensure. Such systems include making resources available for examination preparation so that candidates know what is expected of them, providing a systematic means of addressing any identified gaps in qualifications either via specifically defined courses or a bridging program, establishing occupation-specific language training so that candidates may acquire technical language proficiency and providing assistance to match candidates with employment should Canadian experience be required for licensure. Ideally, upgrading for education and language would be offered by correspondence.

If regulatory bodies adopted these measures, immigrants would not have to take a gamble by immigrating and not knowing whether or when they might actually be able to become licensed. The risk of being forced to take a job below their skill level would be minimized. Indeed, with these measures in place, pre-migration preparation could work to its full potential and truly expedite labour market integration. Immigrants would be able to determine specifically what they need to do in order to practice their profession, how long it will take and how much it will cost.

Currently, there is a great deal of variation in the registration practices of the regulatory bodies. Many have adopted certain initiatives and yet there are other aspects of their practices that pose barriers to the internationally trained and defy an immigrant's ability to plan for labour market entry. None allow applicants to complete licensure from 
abroad. With most, the furthest applicants can proceed in the registration process from overseas is to have their credentials evaluated. A comparison of some of the different registration practices allows for an appreciation of the different scenarios immigrants may encounter in trying to prepare to enter their profession. The examples chosen here are for professions in Ontario because it is the destination of choice for the majority of skilled immigrants to Canada, and also because the Ontario Fairness Commission has compiled extensive information on the registration practices of the regulatory bodies in the province and made it available on their website (www.fairnesscommissioner.ca).

Professional Engineers Ontario (PEO) stands out from other regulatory bodies by the number of steps towards licensing that can be completed from overseas. Candidates may register and submit their academic qualifications for assessment. If there are gaps identified, PEO will assign the candidate technical exams that will allow them to certify to the Canadian standard. Provision has been made for the technical exams to be written overseas and candidates are provided with a list of sources to help them prepare. Being able to write the exams prior to leaving one's home country is crucial because individuals may be assigned anywhere between four and twenty exams and the cost and time involved in preparing these in a position of vulnerability in Canada could very well derail efforts to gain licensure. Once candidates have reached educational equivalency, they must write the Professional Practice Examination, which has also been made available abroad along with online materials to help candidates prepare for the examination (Professional Engineers Ontario, 2008).

Despite these practices which allow candidates to accomplish a great deal from abroad, candidates must still complete one year of work experience in a Canadian jurisdiction under the supervision of a professional engineer before receiving their 
license. To fulfill this requirement, candidates are left entirely to their own devices because PEO neither connects candidates to an appropriate position nor provides any jobfinding support. The regulatory body takes the position that it is not an employment agency and that applicants must take the responsibility for finding a suitable work opportunity themselves. PEO has created an Engineering Intern Training Program through which candidates, for a fee, can obtain advice on how to ensure the work experience opportunity they find will be deemed acceptable. Participation is touted as beneficial for the candidate's résumé because it demonstrates to employers that they are "serious about being licensed as a professional engineer" (Association of Professional Engineers of Ontario, 2002, p.12). However, the program does not help candidates connect to employment in any way.

Certified Management Accountants of Ontario (CMAO) provides another example of mixed initiatives and practices. Candidates can have their language and credentials assessed from overseas. For language, candidates can access an online tool to evaluate their English skills in specific relation to examination requirements. Upon arrival in Canada, they can also access different levels of occupation-specific language training ranging from certification examination preparation to professional development and strategic leadership. For credentials, CMAO issues a report indicating which study topics from a required list have been successfully completed and which are lacking. The study topics correspond to specific university courses for the CMA program in Canada and thus in the latter case, the candidates can take defined courses to obtain equivalency. Some courses have been made available online. CMAO has also developed a seven-month accelerated bridging program to address gaps in candidates' education and prepare them for the certification examination which has been made available by correspondence. 
However, the regulatory body has not made provision for the tests at the end of each module to be written overseas and therefore, the program still cannot be completed from abroad. It is the same situation for the certification examination. Candidates must wait until they arrive in Ontario. Furthermore, candidates must undertake two years of fulltime work experience in Canada in order to complete the licensure process, and again, they must find an employment opportunity on their own. Contrary to Professional Engineers Ontario, however, CMAO provides some support in the form of referrals to settlement and employment organizations across Ontario that assist newcomers in finding work. Still, international candidates cannot ascertain whether they will be able to find an appropriate work experience opportunity and how long it will take (Certified Management Accountants of Ontario, 2008).

Other regulatory bodies have not adapted their practices or procedures in any significant way to reach out to the internationally trained. All that physiotherapists destined for Ontario can do from overseas is mail in their credentials for evaluation along with their standardized language assessment test results. Given that the assessment is standardized, candidates cannot develop any understanding of where they stand with respect to technical proficiency. If gaps in training are identified, there are no courses available by correspondence orany bridging program to enroll in upon arrival in Ontario to expedite entry into the profession. Candidates must also undertake both a written competency and clinical practice examination that candidates once in Canada. From abroad, they cannot determine how long it will take to pass the examinations. While there is a preparation course for the content of the written competency exam, there is no language component for either. If candidates' technical language proficiency is not strong, there is no system in place to prevent them from becoming trapped in a cycle of 
attempting the exams over and over again.

Internationally trained dentists destined for Ontario face a particularly onerous registration process. They must complete a long and costly two-year university qualifying program regardless of how long they have been practicing. Applicants must also write a general examination for which there are no exemptions (Royal College of Dental Surgeons of Ontario, 2008). The exam is difficult to prepare for because there is no blueprint provided. Compare this, for example, to the exam for dental hygienists, for which there is a blueprint, sample questions and answers and an online preparatory mock exam (College of Dental Hygienists of Ontario, 2008). No amount of pre-migration preparation can expedite labour market entry for internationally trained dentists.

For pre-migration preparation to work to its full potential to improve the labour market integration of skilled immigrants, therefore, the regulatory bodies need to make changes to their registration practices. Some regulatory bodies have cited a lack of capacity for failing to provide bridging programs, occupation-specific language training and the facilitation of written examinations abroad (OFC, 2008). However, the Foreign Credentials Recognition Program is currently offering funding for the development of such initiatives (HRSDC, 2009). For example, the Canadian Association of Occupational Therapists has recently received support to identify pathways regarding assessment of credentials and competencies, remediation strategies, and certification. Some of the provincial governments are also offering funding. For example, the Ontario Ministry of Citizenship and Immigration is presently inviting proposals for bridging projects to improve access to occupational certification for the internationally trained (Ontario Ministry of Citizenship and Immigration, 2009). Similarly, the Alberta government has established a Foreign Qualification Innovation Fund to support capacity building for both 
assessment and bridging (Government of Alberta, 2008). The opportunity, therefore, exists for regulatory bodies to implement similar initiatives and the onus lies on them to take advantage of it.

Ontario, Manitoba and Nova Scotia have also established Fairness Commissions to work with the regulatory bodies to impel them to remove barriers to registration. The Ontario Fairness Commission, for example, requires the bodies to complete annual reports that forces them to examine each aspect of their practices and consider whether it could be made more accessible. For example, they have suggested that requirements for paid Canadian work experience, as in the case of Engineers and Management Accountants, be based on additional coursework, volunteer experience or unpaid internships (OFC, 2008).

\section{The role of employers in pre-migration preparation}

The non-regulated professions are different from the regulated ones, again, because there is no accreditation process with a set of qualification requirements regulated by provincial law. Potential applicants deal directly with employers and employment requirements can vary from very general to very specific. It is up to the employer to determine whether an applicant's credentials and language skills are sufficient for the job in question. This can make it very difficult to prepare from overseas and determine whether they will require upgrading or retraining.

However, there are certain things immigrants can do from their home country. They can contact an association or organization relevant to their occupation or sector to try to determine whether there is a procedure for assessment of qualifications that is accepted or preferred. Voluntary certification is available for some non-regulated occupations, for 
example, information technology professionals in Ontario, and immigrants can learn what the requirements are and apply. They can also try to contact employers to learn if there are any general or specific requirements and expectations in the sector. Further, they can have their credentials assessed by one of the major evaluation services such as World Education Services or International Qualifications Assessment Services. While there is no guarantee these evaluations will be accepted by employers, they can validate educational credentials and, at the very least, they can provide the individual with an understanding of where they stand in terms of their academic training.

In order for pre-migration preparation to expedite labour market integration, employers need first to be open towards and interested in hiring the internationally trained, and second to take certain initiatives in connecting to them from abroad. Connecting to immigrants from abroad would involve recruiting, giving serious consideration to overseas applications or providing opportunities for online mentoring or internships. Currently, outreach to skilled workers overseas is limited. The majority of current outreach is being facilitated by the Canadian Immigration Integration Project. Selected employers such as Scotiabank are recruiting through the CIIP offices by hosting tele-seminars and encouraging appropriately trained workers to apply directly to them. Jewish Vocational Services has been facilitating a mentoring program for IT professionals through CIIP offices both online and by video. The CIIP is also developing a database of its skilled worker participants who are job-ready so that employers may connect to them from abroad to make offers of employment. With the Project terminating in 2010 , however, it remains to be seen how much employer outreach will be a focus in the future because requirements in the Call for Proposals for new service providers make no provisions in this respect (FCRO, 2009). 
Alboim argues that, at present, employers do not give enough consideration to the Federal Skilled Worker Class as a potential pool of labour (2009). In fact, surveys of employers by both the Canadian Labour and Business Centre (Lochhead, 2003) and the Public Policy Forum (Lopes and Poisson, 2004) found that hiring immigrants with foreign training ranked at the bottom of the list of possible strategies to meet labour shortages. When employers do need to address specific and immediate labour shortages, recruitment is currently carried out through the Federal Temporary Foreign Worker Program and the Provincial Nominee Program. To change this, Alboim has called for an expansion of recruitment sessions of Federal Skilled Workers in the Canadian Immigration Integration Project offices and other locations as well as an expansion of the online database of job-ready immigrants that employers may access (2009).

Indeed, employers need encouragement to overcome the reticence demonstrated towards the hiring of immigrants. As discussed above, there are a host of reasons why employers do not hire immigrants at a level commensurate with their skills and experience, ranging from the inability to understand the value of foreign credentials and experience to the perception, conscious or unconscious, of immigrants as deficient. There has been a proliferation of initiatives in recent years, however, to counter such reticence and encourage employers to tap into skilled immigration fully. These have developed particularly with support from the Foreign Credential Recognition Program.

The Foreign Credential Referral Office website has developed an Employer Roadmap which provides guidance to businesses of small and medium size on how to recruit, hire and assess the qualifications of foreign trained workers, as well as integrate and retain employees with different cultural and professional backgrounds. There are similar resources and tools that have been developed by the provincial governments and 
numerous not-for-profit agencies across Canada.

The Toronto Region Immigrant Employment Council (TRIEC) works directly with employers to encourage the hiring of immigrants. It has managed to engage hundreds of employers from all sectors in its mentoring program by promoting the benefits of working with internationally trained talent. It also has an awards program to recognize employers who have taken the initiative to connect to the foreign-trained, thereby raising the profile of the hiring of immigrants. One of its web-based programs, Hireimmigrants.ca, is now available across Canada, providing a comprehensive range of information, videos and interactive tools on hiring, integrating and retaining the internationally trained. It offers 'how-to' tele-conference workshops for human resource professionals on topics such as cross-cultural interviewing and the development of organizational cultural competence, as well as tele-seminars on issues such as religious accommodation in the workplace and solutions to language barriers.

Many sector councils have likewise brought skilled immigration to the forefront of their human resource planning. The Information and Communications Technology Council, for example, has marked Internationally Educated Professionals as the main solution to skills shortages in the IT sector and it has developed the well-publicized Internationally Educated Professional Integration Initiative to assist employers in building capacity for the hiring and retaining of skilled newcomers. Such initiatives need to continue and employers need to be increasingly responsive.

\section{Conclusion}

Pre-migration preparation was developed by the federal government as a strategy to expedite economic integration and improve the employment outcomes of skilled 
immigrants by allowing them to circumvent many of the barriers that currently exist in the Canadian labour market through the provision of information, referral and pathfinding. The online and in-person resources developed introduce the issues of credential evaluation and language assessment, allow users to identify and initiate the steps that are needed to enter their profession, and allow them to make better decisions about immigrating and where to settle. They also create realistic expectations about the challenges of integrating into the Canadian labour market.

The initiatives certainly have a great deal of merit, but the current content and delivery structure of the online resources and in-person services are problematic in some ways. How effective pre-migration preparation can be in accomplishing its aims is thus tenuous. The online resources, particularly the Essential Workbook, provide the user with direction to develop a step-by-step plan to access their profession. However, the resources fail to give a full picture of the challenges immigrants face in the Canadian labour market, particularly with regard to insufficient language ability and the low valuation of foreign work experience. The information and referral they provide is also incomplete in other respects. For example, the Working in Canada Guide and Tool do not offer any information on overseas language training opportunities, and the education and training section in the Tool is often empty. The information is occupation-specific, but it is not job-specific. In addition, there is no direction on the key issue of credential evaluation for non-regulated occupations in any of the resources. Material on the important topic of Canadian workplace norms and culture is missing, too. Finally, the Bridge Training programs offered in different sectors across the country are not listed or referenced anywhere.

The online delivery of the Working in Canada Guide, Tool and Essential Workbook 
assumes that individuals applying as skilled immigrants all have access to the internet, as well as a high level of navigational skill and ability to make sense of the complex issues of occupational requirements and credential evaluation. However, focus groups have noted that internet access is not a given, nor is the high level of official language and navigation facility needed to benefit fully from the resources. The fact that in-person services are offered as an alternative or supplement to the internet resources betrays the difficulties involved in accessing or interpreting them without assistance. Offering the services in China in the native language also reflects the complexity of the online content and the need for guidance. The Essential Workbook, for example, does a good job of communicating the issues surrounding credential evaluation, the likelihood of the need for immigrants to upgrade their education, and the cost and time involved in accessing one's profession. What good is it, however, if skilled immigrants cannot access or interpret it? Given the potential impact of this information on preparation and labour market outcomes, it needs to be communicated in other forms and other languages and made available at all other points of contact between Citizenship and Immigration Canada and prospective immigrants.

Skilled immigrants clearly need personal assistance preparing for the labour market, and therefore the in-person services offered thus far through the Canadian Immigration Integration Project are a positive initiative. Participants are introduced to the available resources on employment and the labour market and provided with practical assistance and guidance. The individual counseling sessions afford the opportunity to address participants' specific situations. However, the brevity of the group information and individual counseling sessions severely restricts the benefits to be derived. A single day and a single hour affords the opportunity for no more than a basic treatment of the 
issues at hand. Pinning down the requirements for employment is a complex task. Once participants go away and explore the online resources on their own (assuming participants have good internet access), they will undoubtedly need further direction. Once again, by offering the in-person services in the first place, the federal government is acknowledging that these are difficult issues to tackle without assistance. To offer that assistance for such a brief window of time defeats the purpose, however. Participants need to be able to access ongoing support throughout the pre-migration period. As it stands, many participants may emerge with no more than an understanding of the issues surrounding credential assessment and a referral to a settlement agency at their destination where they can pursue the matter further. The delivery model for the inperson services after the termination of the Canadian Immigration Integration Project in 2010 clearly requires modification to be more useful.

Accessibility of the in-person services places another serious restriction on their effectiveness. Currently, they are only offered in select cities. The discrepancy between the number of eligible candidates who registered and the number who actually attended the sessions attests to the difficulty in traveling to access the services. The number of cities certainly needs to be increased. In addition, offering the services at the final stage of the immigration process limits the amount of preparation that can be undertaken. For skilled immigrants to be able to address gaps in their education and language before they arrive in Canada, they need to be able to identify them in good time.

To review, the major barriers to the labour market integration of immigrants include the following: lack of recognition of foreign credentials and experience, lack of Canadian experience, insufficient official language ability, current hiring practices and newcomers' lack of social networks, lack of information regarding employment, negative 
employer attitudes and discrimination. Pre-migration preparation addresses the nonrecognition of credentials by allowing immigrants to undertake evaluations that will help employers understand the value of their education and by allowing them to have their credentials evaluated in advance in order that they may identify gaps and upgrade to the Canadian standard. It addresses insufficient official language ability by emphasizing the importance of proficiency and encouraging language assessment and the upgrading of skills. Further, it addresses the lack of social networks in a limited way by supplying some opportunities for e-mentoring.

Most of all, though, pre-migration preparation addresses the lack of information on issues relating to employment and the labour market by providing occupation-specific and destination-specific material and direction to immigrants. This accomplishes the crucial task of raising awareness of the time and cost required to access one's profession and other challenges that immigrants face in transitioning to the Canadian labour market. In this way, pre-migration preparation works to eliminate the gap in expectations that results from the messages conveyed by the points system and the actual valuation of immigrant qualifications in that market. This is critical because false expectations result in increased susceptibility to taking survival jobs because sufficient planning has not taken place.

Pre-migration preparation is promising in terms of raising awareness and allowing skilled immigrants to plan and upgrade, but it is powerless to address the other barriers to labour market integration. The extent to which it can thus actually expedite labour market entry is limited. The government is currently trying to address some of the other barriers with efforts to standardize foreign credential evaluation under the Foreign Credential Recognition Program and with increased funding to settlement programs, including 
Bridge Training and Enhanced Language Training. However, culpability for the remaining and most significant barriers lies with the regulatory bodies and employers. The number of steps immigrants are able to take towards registration and employment from overseas is determined by these two groups, but how much access immigrants have to the regulated and non-regulated professions at all is determined by them as well. There is nothing immigrants can do to overcome unfair or unduly burdensome registration practices, hiring practices that exclude newcomers, or the perception of immigrants as deficits. The federal government has a responsibility to facilitate the economic integration of the Federal Skilled Workers that it attracts and therefore the onus lies on it to induce the regulatory bodies and employers to change their attitudes and practices and adopt a more pro-active approach towards the internationally trained. The economic outcomes of skilled immigrants cannot improve and Canada's economic immigration program cannot succeed without this kind of change.

\section{References}

Alboim, N. and The Maytree Foundation. (2002). Fulfilling the Promise: Integrating Immigrant Skills into the Canadian Economy. Ottawa: Caledon Institute of Social Policy.

Alboim, N. and The Maytree Foundation. (2009). Adjusting the Balance: Fixing

Canada's Economic Immigration Policies. Ottawa: Caledon Institute of Social Policy.

Alboim, N., R. Finnie, and R. Meng. (2005). “The Discounting of Immigrants' Skills in Canada: Evidence and Policy Recommendations". IRPP Choices, 11(2). Alboim, N. and E. McIsaac. (2007). "Making the Connections. Ottawa's Role in 
Immigrant Employment". IRPP Choices, 13(3).

Asia Pacific Foundation of Canada. (2005). Canada Faces Growing Competition for

Immigrants to Ease Skills Crisis. Asia Pacific Bulletin \#199. Accessed on May 12, 2009 at www.asiapacific.ca/en/apbn/pdfs/bulletin199.pdf.

Association of Canadian Community Colleges. "The Canadian Immigration Integration

Project." http://ciip.accc.ca/

Association of Canadian Community Colleges. (2008a). The Canadian Immigration Integration Project Post. 1(2).

Association of Canadian Community Colleges. (2008b). The Canadian Immigration Integration Project Post. 1(3).

Association of Canadian Community Colleges. (2009). Canadian Immigration

Integration Project Report on Statistics: January 01,2007- December 31, 2008. Ottawa, ON.

Association of Professional Engineers of Ontario. (2002) Guide to the Required Experience for Licensing as a Professional Engineer in Ontario. Accessed on July 23, 2009 at www.peo.on.ca/registration/RequiredExpForLicensing.pdf Aydemir, A. and C. Robinson. (2006). Return and Onward Migration among Working Age Men. Ottawa: Statistics Canada. Catalogue No. 11F0019MIE-No. 273.

Aydemir, A. and M. Skuterud. (2004). Explaining the deteriorating entry earnings of Canada's immigrant cohorts: 1966-2000. Ottawa: Statistics Canada. Catalogue No. 11F0019MIE- No. 225.

Baker, M. and D. Benjamin. (1994). "The performance of immigrants in the Canadian labour market." Journal of Labor Economics. 12 (3): 369-405. 
Baldwin, J.R., and D. Beckstead. (2003). Knowledge Workers in Canada's Economy, 1971-2001. Ottawa: Statistics Canada. Catalogue No. 11-624-MIE No. 004.

Becker, G. (1993). Human Capital: A Theoretical and Empirical Analysis with Special Reference to Education. Chicago: University of Chicago Press.

Biles, J. (2008). “Integration Policies in English Speaking Canada.” In J. Biles, M. Burnstein and J. Frideres (Eds.), Immigration and Integration in Canada in the Twenty-First Century. Montreal \& Kingston: McGill-Queen's University Press, pp. 139-186.

Birrell, B., L. Hawthorne and S. Richardson, editors. (2006). Evaluation of the General Skilled Migration Categories. Canberra: Department of Immigration and Multicultural Affairs.

Bloom, M. and M. Grant. (2001). Brain Gain: The Economic Benefits of Recognizing

Learning and Learning Credentials in Canada. Conference Board of Canada.

Bloom, D., G. Grenier and M. Gunderson. (1995). "The changing labour market position of Canadian immigrants." Canadian Journal of Economics. 28 (4b): 987-1005.

Brouwer, A. (1999). Immigrants Need Not Apply. Ottawa: Caledon Institute of Social Policy.

Canada Gazette. (2002). Part II. Volume 136. No. 9. Pages 1-449. Immigration and Refugee Protection Regulations. 14 June.

Canadian Federation of Independent Business. (2000). Hard Facts Survey on Business Expectations, 2000. Accessed on May 16, 2009 at http://www.cfib.ca/research/reports/facts2000 e.asp.

Certified Management Accountants of Ontario. (2008). Fair Registration Practices 
Report. Accessed on August 16, 2009 at

http://www.fairnesscommissioner.ca/en/about/current projects/frp reports.php

Citizenship and Immigration Canada. (2005). "Report on the Evaluation of the Delivery

of the Canadian Orientation Abroad Initiative." Ottawa, ON. Accessed on July 1, 2009 at http://www.cic.gc.ca/english/resources/evaluation/orientation.asp\#response

Citizenship and Immigration Canada. (2007). "Backgrounder: Foreign Credentials

Referral Office." Ottawa, ON. Accessed on July 2, 2009 at

http://www.credentials.gc.ca/media/backgrounders/2007-05-24.asp

Citizenship and Immigration Canada. (2008a). "News Release: Government of Canada helps immigrants achieve success in Canada." Ottawa, ON. Accessed on July 2, 2009 at

http://www.cic.gc.ca/english/DEPARTMENT/MEDIA/RELEASES/2008/2008-03$\underline{20 a . a s p}$

Citizenship and Immigration Canada. (2008b). "Backgrounder: Ministerial Instructions." Ottawa, ON. Accessed on July 25, 2009 at http://www.cic.gc.ca/english/DEPARTMENT/MEDIA/backgrounders/2008/200811-28a.asp

Citizenship and Immigration Canada. (2009). "Planning to work in Canada? An essential workbook for newcomers". Ottawa, ON. Accessed on July 2, 2009 at http://www.credentials.gc.ca/immigrants/workbook/index.asp

College of Dental Hygienists of Ontario. (2008). Fair Registration Practices Report. Accessed on August 16, 2009 at http://www.fairnesscommissioner.ca/en/about/current projects/frp reports.php 
Conference Board of Canada. (2000). Performance and Potential 2000-2001: Seeking Made in Canada Solutions. Accessed on May 16, 2009 at http://www.conferenceboard.ca/documents.aspx?did=256.

Dietz, J., V. Esses, C. Joshi, C. Bennett-AbuAyyash. (2009). The Evaluation of Immigrants' Credentials: The Roles of Accreditation, Immigrant Race, and Evaluator Biases. Canadian Labour Market and Skills Researcher Network Working Paper No. 18.

Economic Council of Canada. (1991). Economic and Social Impacts of Immigration.

Ottawa: Economic Council of Canada.

EKOS Research Associates Inc. (2007). "Qualitative Research on the 'Working in Canada' Tool of the Going to Canada Immigration Portal." Ottawa, ON. Accessed on July 1,2009 at

http://www.hrsdc.gc.ca/eng/publications resources/por/subjects/skills and employ $\underline{\text { ment } / 2007 / 32206 / \text { page } 00 . \text { shtml }}$

Foreign Credentials Referral Office. (2009). "Call for proposals - Orientation sessions on foreign credential recognition." Accessed on August 16, 2009 at http://www.credentials.gc.ca/partners/cfp/sectionA.asp\#a02e

Frenette, M., and R. Morissette. (2003). Will They Ever Converge? Earnings of Immigrant and Canadian-born. Ottawa: Statistics Canada. Catalogue No. 11F0019MIE- No. 215.

Galarneau, D. and R. Morrissette. (2004). “Immigrants: Settling for Less?” Perspectives on Labour and Income. 5 (6): 5-16.

Government of Alberta. (2008). A Foreign Qualification Recognition Plan For Alberta. Calgary: Government of Alberta. 
Grant, M. L. (1999). "Evidence of new immigrant assimilation in Canada". Canadian Journal of Economics. 32(4): 930-955.

Green, A. and D. Green. (2004). "The Goals of Canada's Immigration Policy: A Historical Perspective." Canadian Journal of Urban Research. 13 (1): 102-139.

Green, D. A. and C. Worswick. (2003). "Immigrant Earnings Profiles in the Presence of Human Capital Investment: Measuring Cohort and Macro Effects." Paper presented at Society of Labor Economists (SOLE) annual meeting. Toronto, September 2003.

Hawthorne, L. (2006). Labour market outcomes for migrant professionals: Canada and Australia Compared. Ottawa: Citizenship and Immigration Canada. Accessed on May 16, 2009 at http://www.cic.gc.ca/ENGLISH/resources/research/2006canada-australia.asp.

Hawthorne, L. (2008). "The Impact of Economic Selection Policy on Labour Market Outcomes for Degree-Qualified Migrants in Canada and Australia". IRPP Choices, 14(5).

Hiebert, D. (2006). "Beyond the Polemics: The Economic Outcomes of Canadian Immigration." Metropolis British Columbia Working Paper Series 06-15.

Human Resources and Skills Development Canada. (2001). "Earnings and Employment Patterns." Applied Research Bulletin. 7 (1). Ottawa: Government of Canada.

Human Resources and Skills Development Canada. (2002). "Knowledge Matters: Skills and Learning for Canadians." Ottawa, ON. Accessed on May 16, 2009 at http://www.ilo.org/public/english/employment/skills/hrdr/init/can 1.htm\#kuva.

Human Resources and Skills Development Canada. (2005a). "Overview:

The Internationally Trained Workers Initiative." Ottawa, ON. Accessed on July 13, 
2009 at http://www.hrsdc.gc.ca/eng/cs/comm/hrsd/news/2005/050425bg.shtml

Human Resources and Skills Development Canada. (2005b). "Backgrounder: Going to

Canada Information Portal." Ottawa, ON. Accessed on July 2, 2009 at

http://www.hrsdc.gc.ca/eng/cs/comm/hrsd/news/2005/050425be.shtml

Human Resources and Skills Development Canada. (2007). Formative Evaluation of the

Foreign Credential Recognition Program. Ottawa, ON. Accessed on July 2, 2009

at http://www.hrsdc.gc.ca/eng/publications resources/evaluation/2007/

sp ah $687 \quad 02 \quad 07 /$ page01.shtml

Human Resources and Skills Development Canada. (2009). "Project Funding- Foreign

Credential Recognition." Ottawa, ON. Accessed on July 31, 2009 at

http://www.hrsdc.gc.ca/eng/workplaceskills/credential recognition/funding.shtml

Li, P. (2000). "Earning disparities between immigrants and native-born Canadians".

Canadian Review of Sociology and Anthropology. 37 (3): 289-311.

Liu, E. (2007). “A Descriptive Study of Employers' Attitudes and Practices in Hiring

Newcomer Job Seekers". CERIS. Policy Matters No. 31.

Lochhead, C. (2003). "Perspectives on Immigration: Findings from the Canadian Labour

and Business Centre's Survey of Canadian Business, Labour and Public Sector

Leaders". Canadian Labour and Business Centre Publications. Accessed on April

2, 2009 at http://www.clbc.ca/Fitting_In/Perspectives_on_Immigration.aspo.

Lochhead, C. and P. Mackenzie. (2005). "Integrating Newcomers into the Canadian

Labour Market." Canadian Issues. (Spring): 35-38.

Lopes, S. and Y. Poisson. (2004). Bringing employers into the immigration debate:

Survey and conference. Public Policy Forum. Ottawa, ON. Accessed on April 2, 2009 at http:/www.ppforum.ca/common/assets/publications/en/ 
bringing employers into the immigration debate.pdf.

MacDougall, A. (2007). Hearing Audible Minorities: Accent, Discrimination, and the Integration of Immigrants into the Canadian Labour Market. Toronto: Ryerson University, School of Graduate Studies. Program in Immigration and Settlement Studies.

Man, G. (2004). "Gender, Work and Migration: Deskilling Chinese Immigrant Women in Canada". Women's Studies International Forum. 27 (2): 135- 148.

Mata, F. (1994). "The Non-Accreditation of Immigrant Professionals in Canada: Societal Impacts, Barriers and Present Policy Initiatives." Paper presented at the Sociology and Anthropology Meetings of the 1994 Learned Societies Conference, University of Calgary, June 3-18. Accessed on June 21, 2009 at http://canada.metropolis.net/researchpolicy/conversation/MATAPAPER.html\# Toc462031393

Murray, K. (2007a). "Canadian Immigration Integration Project: A Stitch in Time." Canadian Issues. (Spring): 47-49.

Murray, K. (2007b). Enabling immigration integration: on site overseas, online and on arrival; Canadian Immigration Integration Project. Metropolis Conference Presentation. Melbourne, Australia. October 11, 2007.

Ontario Office of the Fairness Commissioner. (2008). Ontario's Regulated Professions: Report on the 2007 Study of Registration Practices. Toronto: Queen's Printer for Ontario.

Ontario Ministry of Citizenship and Immigration. (2009). "Bridge Training Programs for Internationally Trained Individuals 2009-2010.” Toronto, ON. Accessed on July 31, 2009 at 
http://www.citizenship.gov.on.ca/english/working/experience/IFP/index.shtml

Ontario Ministry of Training, Colleges and Universities. (2002). The Facts Are In! A study of the characteristics and experiences of immigrants seeking employment in regulated professions in Ontario. Toronto: The Ministry of Training, Colleges and Universities.

Owen, T. and S. Lowe. (2008). Labour Market Integration of Skilled Immigrants:

Good Practices for the Recognition of International Credentials. Paper presented at the Expert Group Meeting on Migration and Education: Quality Assurance and Mutual Recognition of Qualifications, UNESCO Headquarters Paris, September 22-23. Accessed on June 30, 2009 at http://ceris.metropolis.net/Virtual\%20Library/Index.htm

Pendakur, K. and R. Pendakur. (1998). “The Colour of Money: Earnings Differentials Across Ethnic Groups in Canada." Canadian Journal of Economics. 31(3): 518548.

Picot, G. (2004). "The Deteriorating Welfare of Canadian Immigrants.” Canadian Journal of Urban Research. 13 (1): 25-45.

Picot, G., F. Hou, and S. Coulombe. (2007). Chronic Low-Income and Low-Income Dynamics among Recent Immigrants. Ottawa: Statistics Canada. Catalogue No. 11F0019MIE, No. 294.

Policy Roundtable Mobilizing Professions and Trades [PROMPT]. (2004). In the Public Interest. Immigrant Access to Regulated Professions in Today's Ontario. Toronto, ON.

Professional Engineers Ontario. (2008). Fair Registration Practices Report. Accessed on 
August 16, 2009 at

http://www.fairnesscommissioner.ca/en/about/current projects/frp reports.php

Progress Career Planning Institute. (2009). Best Practices: Employers and IEPs Speak

about Strategies for Integrating Internationally Educated Professionals into the

Canadian Labour Force. Toronto, ON. Accessed on April 1, 2009 at

http://www.compas.ca/polls/090311-IEP-B.htm

Reitz, J. (2001a). "Immigrant Skill Utilization in the Canadian Labour Market:

Implications for Human Capital Research.” Journal of International Migration and Integration. 2 (3): 347-378.

Reitz, J. (2001b). "Immigrant Success in the Knowledge Economy: Institutional Change and the Immigrant Experience in Canada, 1970-1995." Journal of Social Issues. 57 (3): 579-613.

Reitz, J. (2003). “Occupational Dimensions of Immigrant Credential Assessment: Trends in Professional, Managerial, and Other Occupations, 1970-1996.” In Canadian Immigration Policy for the 21st Century, edited by Charles Beach, Alan Green, and Jeffrey G. Reitz. Kingston: John Deutsch Institute for the Study of Economic Policy.

Reitz, J. (2005). “Tapping Immigrants' Skills: New Directions for Canadian Immigration Policy in the Knowledge Economy". IRPP Choices, 11 (1).

Royal College of Dental Surgeons of Ontario. (2008). Fair Registration Practices Report. Accessed on August 16, 2009 at http://www.fairnesscommissioner.ca/en/about/current projects/fip reports.php Ruddick, E. (2008a). "Immigration to Canada: Trends and Policy Challenges". 
Citizenship and Immigration Canada. Presentation at Carleton University, Ottawa, November 25, 2008. Accessed on May 16, 2009 at http://integrationnet.ca/english/videos/video.cfm?M=9.

Ruddick, E. (2008b). "Onward/Circular Migration and Integration: A Canadian Perspective." Citizenship and Immigration Canada. Presentation at $13^{\text {th }}$ International Metropolis Conference Bonn, October, 2008. Accessed on May 16, 2009 at www.metropolis2008.org/pdf/20081028/workshops/w001-28 ruddickelizabeth.pdf.

Sangster, D. (2001). "Assessing and Recognizing Foreign Credentials in Canada Employers' Views." Ottawa: Canadian Labour and Business Centre.

Accessed on June 30, 2009 at

http://atwork.settlement.org/sys/atwork library detail.asp?doc id=1002720\&passe d lang=EN

Scassa, T. (1994). "Language Standards, Ethnicity and Discrimination." Canadian Ethnic Studies. 26 (3): 105-121.

Schaafsma, J. and A. Sweetman. (2001). "Immigrant earnings: age at immigration matters." Canadian Journal of Economics. 34 (4): 1066-1099.

Schellenberg, G. and H. Maheux. (2007). Immigrants' perspectives on their first four years in Canada: Highlights from three waves of the Longitudinal Survey of Immigrants to Canada. Ottawa: Statistics Canada. Catalogue No. 11-008.

Statistics Canada. (2003a). Earnings of Canadians: Making a living in the new economy. 2001 Census Analysis Series. Catalogue No. 96F0030XIE2001013.

Statistics Canada. (2003b). Longitudinal Survey of Immigrants to Canada: Process, Progress and Prospects. Catalogue no. 89-611. Ottawa, ON. 
Statistics Canada. (2005). Longitudinal Survey of Immigrants to Canada: A Portrait of Early Settlement Experiences. Catalogue no. 89-614-XIE. Ottawa, ON.

Statistics Canada. (2006a). Earnings and Incomes of Canadians Over the Past Quarter Century, 2006 Census. 2006 Census Analysis Series. Catalogue No. 97-563-X.

Statistics Canada. (2006b). Immigration in Canada: A Portrait of the Foreign-born Population, 2006 Census. Catalogue no. 97-557. Ottawa, ON.

Teelucksingh, C. and G.-E. Galabuzi. (2005). Working Precariously: The Impact of Race and Immigrant Status on Employment Opportunities and Outcomes in Canada. Toronto: Canadian Race Relations Foundation.

Toronto Region Immigrant Employment Council [TRIEC]. (2006). To Employment: Services for Skilled Immigrants in the Toronto Region. Toronto, ON.

Warman, C. and C. Worswick. (2004). "Immigrant Earnings Performance in Canadian Cities Through 2001." Canadian Journal of Urban Research. 13 (1): 62-84. Wayland, S. (2006). Unsettled: Legal and Policy Barriers for Newcomers to Canada. Toronto: Community Foundations of Canada and the Law Commission of Canada. Accessed on June 20, 2009 at http://www.cfc-fcc.ca/doc/LegalPolicyBarriers.pdf Weiner, N. (2008). "Breaking Down Barriers to Labour Market Integration of Newcomers in Toronto". IRPP Choices, 14 (10).

Zietsma, D. (2007). The Canadian Immigrant Labour Market in 2006: First Results from Canada's Labour Force Survey. Ottawa: Statistics Canada. Catalogue No. 71606-XIE2007001. 